\title{
Best Student Research Paper Award 2022
}

https://doi.org/10.1515/libri-2021-2003

Since 1950, through 70 volumes, Libri: International Journal of Libraries and Information Studies has been a leader among scholarly journals in the international library and information science world. As part of its strategy to remain one of the premier library and information science journals, Libri is issuing a call for "Best Student Research Paper of 2022." This competition supports Libri's goal of publishing the best articles from the next generation of library and information science professionals. We are proud once again to recognise the very best article with this special award.

Students who are currently enrolled for a Masters or $\mathrm{PhD}$ or who have completed their Masters or PhD during the 24 months preceding the closing date of the competition $^{1}$ are invited to submit papers with clarity and authority. There is no stated theme, but papers should fall within the scope of LIBRI's research focus areas that cover the broad area of library and information science, including but not limited to:

- Libraries (national, public, academic, school, special, etc.) and other information environments

- Information and knowledge management

- Information behaviour

- Information needs, seeking, searching and use

- Information retrieval

- Emerging technologies, including AI, AR, VR etc., from an Information Science perspective

- Information for development (developing and industrialised countries)

- Indigenous knowledge

- Literacy (media, information, etc.)

- Data science, data analytics, big data and their impact on organisations (e.g. customer related data; social science perspective)

- Digital libraries and repositories

- Data science, data management, data curation and virtual research environments (VREs)

- Information ethics, policy and law

1 Exception: Senior information scholars returning to school for additional degrees outside the field of library and information science are not eligible for this award.
- Scholarly communication

- Open science, open access and related topics

- Health information

- Information science

- Information services

- Information in society

- Electronic Data Interchange (EDI)

- Information organisation and representation

- Freedom of access to information and freedom of expression

- Archives \& preservation

- Cultural heritage

- Book and publishing theory and history

- LIS education

- International and comparative LIS research

- Research methodologies in LIS

- Theory submissions

(We do not publish articles on scientometrics, bibliometrics, webometrics, altmetrics etc., as there are a number of specialist journals that does so.)

Research papers should address one of the significant issues facing today's librarians and information professionals. Case studies, best practises and pure research papers are all welcome.

- Length: 5000-7000 words (excluding the abstract, tables and list of references)

- Follow the Instructions for Authors linked from the Libri website at https://www.degruyter.com/journal/ key/libr/html

- Papers by multiple authors (be this joint research of a group of students, or of a student plus their supervisor) will not be considered

- Language: English

- Deadline: June 30, 2022, 23:59 UTC

\section{Plagiarism and patch-writing}

Plagiarism and patch-writing are not acceptable. All content not the author's own intellectual thought (even if the content paraphrases intellectual property of other researchers) should be properly referenced. All manuscripts are automatically put through similarity detection software, and the results are evaluated by the editors. Manuscripts containing plagiarised material or (excessive) patch-writing will be rejected, without the option of revision or resubmission. 
The best paper will be selected by an independent panel consisting of selected members of the Editorial Board, the Advisory Board and other international experts. Submissions will be judged on the basis of

- originality of thought and observation

- depth of research and scholarship

- topicality of problems addressed

- the international readership of the journal

- the quality of the composition

The article will be published in the 2022:4 issue. The author of the winning article will be honoured with an award of $500.00 €$ and with a complimentary subscription to Libri for 2023.

If the quality of competition warrants, some papers may be designated as honourable mention and the authors will receive complementary subscriptions to Libri for 2022. All winners will receive access to e-prints of their winning submission.

Manuscripts should be submitted to http://mc. manuscriptcentral.com/libri. When submitting a paper for the Best Student Research Paper Award, please choose "Best Student Research Paper Award" at the drop-down menu "Manuscript Type."

All submissions should include a cover sheet confirming:

- the name of the institution where the student is or was enrolled

- the degree for which the student is or was enrolled

- the dates when the student is or was enrolled

- the degree/course/module for which the paper was prepared

- the date when the paper was written

\section{PLEASE NOTE:}

Paper submissions who do not include all the above required elements, as well as do not comply with the content requirements specified, will be disqualified for consideration. All papers will also automatically be screened for plagiarism and patchwriting. 